\title{
STUDI ADSORPSI LOGAM Pb(II) DAN Cd(II) PADA ASAM HUMAT DALAM MEDIUM AIR
}

\author{
Atik Rahmawati', Sri Juari Santoso² \\ ${ }^{1}$ Fakultas Tarbiyah, IAIN Wali Songo Semarang \\ ${ }^{2}$ Fakultas MIPA Universitas Gajah Mada Yogyakarta
}

\begin{abstract}
It had been conducted a study on adsorption of $\mathrm{Cd}$ (II) and $\mathrm{Pb}$ (II) of humic acid isolated from peat soil from village of Sambutan, the subdistrict of Samarinda Ilir, East Kalimantan. Aspects studied covered adsorption kinetics and adsorption is otherm of $\mathrm{Cd}$ (II) and $\mathrm{Pb}$ (II) of humic acid in water medium.

Adsorption process carried out by batch method. Kinetics study conducted by intracting metal adsorption of $\mathrm{Cd}$ (II) and $\mathrm{Pb}$ (II) with humic acid at various times, meanwhile studying the adsorption isotherm is done by interacting $\mathrm{Cd}$ (II) and $\mathrm{Pb}$ (II) at various concentrations with humic acid.

The results showed the adsorption rate of $\mathrm{Cd}$ (II) and $\mathrm{Pb}$ (II) on humic acid followed first order with rate constants of $\mathrm{Cd}$ (II) and $\mathrm{Pb}$ (II) of 0.0012 and $0.0038 \mathrm{mg} \mathrm{menit}^{-1} / 10$ humic acid. Carboxylic groups of humic acid as the main groups which were actively involved in the interaction of metal-humic acid and have experienced deprotonation is hard nucleophile. It made $\mathrm{Pb}$ (II) was more quickly and easily adsorbed than $\mathrm{Cd}$ (II). Adsorption is otherm of $\mathrm{Cd}$ (II) and $\mathrm{Pb}$ (II) on humic acid followed the pattern of Langmuir is otherm with adsorption capacities of $\mathrm{Pb}$ (II) of $1.66 \mathrm{x} 10-3 \mathrm{~mol} / \mathrm{g}$ and for Cd (II) $3.83 \mathrm{x} 10-3 \mathrm{~mol} / \mathrm{g}$. The adsorption energy of both metals is relatively small that is equal to 16.1 for $\mathrm{Cd}$ (II) and $21.4 \mathrm{~kJ} / \mathrm{mol}$ for $\mathrm{Pb}$ (II)
\end{abstract}

Key words : adsorption rate, adsorption isotherm, $C d(I I), P b(I I)$, humic acid

\section{ABSTRAK}

Telah dilakukan penelitian tentang adsorpsi logam $\mathrm{Cd}$ (II) dan $\mathrm{Pb}$ (II) pada asam humat hasil isolasi tanah gambut yang berasal dari Desa Sambutan, Kecamatan Samarinda Ilir, Samarinda, Kalimantan Timur. Aspek adsorpsi yang dipelajari meliputi kinetika dan isoterm adsorpsi $\mathrm{Cd}$ (II) dan $\mathrm{Pb}$ (II) pada asam humat dalam medium air.

Proses adsorpsi dilakukan dengan metode batch. Studi kinetika adsorpsi dilakukan dengan menginteraksikan logam $\mathrm{Cd}(\mathrm{II})$ dan $\mathrm{Pb}$ (II) dengan as am humat pada berbagai variasi waktu, sedangkan untuk mempelajari isoterm adsorpsi dilkukan dengan menginteraksikan logam $\mathrm{Cd}$ (II) dan $\mathrm{Pb}$ (II) pada berbagai variasi konsentrasi dengan asam humat.

Hasil penelitian menunjukkan laju adsorpsi $\mathrm{Cd}(\mathrm{II})$ dan $\mathrm{Pb}(\mathrm{II})$ pada asam humat mengikuti orde satu dengan tetapan laju $\mathrm{Cd}(\mathrm{II})$ dan $\mathrm{Pb}$ (II) sebesar 0,0012 dan 0,0038 menit ${ }^{-1} / 10 \mathrm{mg}$ asam humat. Gugus karboksilat sebagai gugus utama asam humat yang berperan aktif dalam interaksi logam-asam humat yang mengalami deprotonasi merupakan nukleofil keras, sehingga $\mathrm{Pb}$ (II) lebih cepat dan mudah teradsorp dibandingkan $\mathrm{Cd}(\mathrm{II})$. Isoterm adsorpsi $\mathrm{Cd}$ (II) dan $\mathrm{Pb}$ (II) pada as am humat mengikuti pola is oterm Langmuir,

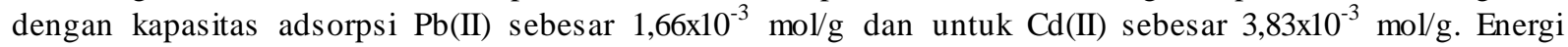
adsorpsi kedua logam relatif kecil yaitu sebesar 16,1 untuk logam $\mathrm{Cd}$ (II) dan 21,4 kJ/mol untuk logam $\mathrm{Pb}$ (II)

Kata kunci : laju adsorbsi, isotherm adsorpsi, logam Cd(II), logam Pb(II), asam humat

\section{PENDAHULUAN}

Unsur kadmium dan timbal secara alamiah merupakan unsur-unsur yang jumlahnya kecil (unsur trace), namun demikian adanya buangan logam tersebut ke lingkungan dalam jumlah besar mengakibatkan lingkungan tercemar dan dapat menyebabkan keracunan terhadap makhluk hidup.

Kadmium termasuk logam yang sangat toksik dan menyebabkan masalah kesehatan pada manusia seperti penyakit bronchitis dan itai-itai, dimana kadmium terakumulasi di ginjal (Liu dan Huang, 1999). Seperti yang menimpa masyarakat di 
sekitar sungai Jinzu di pulau Honsyu Jepang yang telah tercemar kadmium, menderita penyakit yang dikenal dengan penyakit itai-itai. Penyakit ini menyebabkan ratusan orang meninggal di daerah tersebut akibat terakumulasi kadmium dalam jaringan tubuhnya. Sementara itu keracunan logam timbal pada manusia diketahui menyebabkan penyakit anemia.

Beberapa metode telah dikembangkan untuk mengurangi kandungan logam berat dari air buangan, seperti koagulasi, kompleksasi, ekstraksi pelarut, pertukaran ion, dan adsorpsi. Metode adsorpsi umumnya berdasarkan interaksi logam dengan gugus fungsional yang ada pada permukaan adsorben melalui interaksi pembentukan kompleks. Adsorpsi ini biasanya terjadi pada permukaan padatan yang kaya akan gugus fungsional seperti : - OH, -NH, -SH dan $-\mathrm{COOH}$ (Stumm dan Morgan, 1996).

Pengikatan logam oleh bahan organik penting untuk dipelajari mengingat spesiasi logam-logam dalam cairan limbah buangan didominasi oleh kompleks organik-logam, dan di lingkungan tanah keberadaan logam-logam juga dipengaruhi oleh bahan organik tanah khususnya senyawa humat (Chung dkk., 1996).

Kemampuan senyawa humat membentuk kompleks yang stabil dengan kation-kation polivalen telah dilaporkan oleh beberapa peneliti (Stevenson, 1982 dalam Aiken dkk., 1985). Pembentukan kompleks tersebut memfasilitasi: mobilisasi, transport, deposisi logam trace dalam tanah, sedimen, batuan endapan dan deposit biogenik. Kompleks organik memainkan peran kunci pada pelapukan batuan, serta berfungsi sebagai pembawa kation logam dalam air alami (Stevenson dan Ardakani, 1972; Stevenson, 1983 dalam Aiken dkk., 1985).

Meskipun banyak penelitian yang telah dilakukan tentang interaksi asam humat dengan ion-ion logam (Stevenson, 1977; Sposito, 1986 dalam Zavarzina dkk, 2000) dan beberapa model telah ditemukan untuk memberikan gambaran dari kompleksasi ion-ion logam dengan senyawa humat (Tipping \& Hurley, 1992; Benedetti dkk., 1995 dalam Zavarzina dkk, 2000), namun penelitian tentang hal ini masih memerlukan pengamatan yang lebih jauh mengingat asam humat merupakan bahan organik alami yang sangat heterogen dan kompleks.

Berdasarkan uraian di atas, maka dalam penelitian ini ada beberapa permasalahan pokok yang dikemukakan yaitu : (1) bagaimana laju adsorpsi logam $\mathrm{Cd}$ (II) dan $\mathrm{Pb}$ (II) pada asam humat? (2) bagaimana pola isoterm dan berapa kapasitas adsorpsi logam $\mathrm{Cd}$ (II) dan $\mathrm{Pb}$ (II) pada asam humat? (3) berapa energi adsorpsi logam $\mathrm{Cd}(\mathrm{II})$ dan $\mathrm{Pb}$ (II) pada asam humat?

\section{LANDASAN TEORI}

\subsection{Logam dalam Sistem Perairan}

Spesiasi logam transisi dalam sistem perairan alamiah pada prinsipnya diatur oleh : (1) $\mathrm{pH}$, (2) jenis dan kepekatan ligan dan senyawa-senyawa pengkhelat dalam perairan, dan (3) keadaan oksidasi komponen mineral dan lingkungan redoks sistem tersebut (Leckie dan James, 1974 dalam Connell dan Miller, 1995). Interaksi dinamis pada batas larutan-padatan menentukan perpindahan logam antara fase cair dan fase padat. Dengan demikian, logam transisi dapat berada dalam bentuk endapan, koloid atau larutan.

Semua kation logam dalam air berada dalam keadaan ion logam terhidrat $\left[\mathrm{M}\left(\mathrm{H}^{2} \mathrm{O}\right)_{\mathrm{x}}{ }^{\mathrm{n}+}\right]$ dan spesies hidroksi $\left[\mathrm{MOH}\left(\mathrm{H}_{2} \mathrm{O}\right)_{\mathrm{x}-1}{ }^{+(\mathrm{n}-1)}\right]$ dimana kation-kation logam tersebut membentuk kompleks aquo. Reaksi koordinasi yang melibatkan kation logam pada larutan berair adalah reaksi pertukaran ligan air yang terkoordinasi dengan ligan, baik anion anorganik maupun molekul organik. Fenomena dimana ligan mampu mengikat logam pada lebih dari satu tempat disebut pengompleksan atau pengkhelatan (Stumm dan Morgan, 1996).

Senyawa humat merupakan agen pengkhelat penting yang terjadi secara 
alamiah. Kemampuan mengikat ion logam merupakan salah satu sifat dari senyawa humat. Ikatan dapat terjadi sebagai khelat antara gugus karboksilat dan gugus fenol, sebagai khelat antar dua gugus karboksilat atau sebagai kompleks dengan gugus karboksilat (Manahan, 2000).

\subsection{Asam Humat sebagai Adsorben}

Salah satu karakteristik utama asam humat sebagai bagian dari fraksi oganik tanah gambut adalah kemampuannya mengadsorpsi bahan organik dan anorganik. Kemampuan senyawa humat berinteraksi dengan kation logam disebabkan oleh sebagian besar gugus-gugus fungsional asam humat mengandung atom oksigen seperti $-\mathrm{COOH}$, fenolat, enolat, $-\mathrm{OH}$ alkoholat dan $-\mathrm{C}=\mathrm{O}$.

Berdasarkan keberadaan senyawa humat yang heterogen, interaksi kation logam dengan senyawa humat terjadi pada sejumlah besar sisi aktif, dengan afinitas yang berbeda. Interaksi ion logam divalen maupun trivalen dengan asam humat atau asam fulvat dalam medium air pada $\mathrm{pH}$ mendekati 7, dapat berlangsung melalui pembentukan ikatan hidrogen atau jembatan air, interaksi elektrostatik atau pertukaran ion, ikatan koordinasi dan melalui struktur cincin khelat. Pengikatan kation logam terjadi pertama kali melalui interaksi yang menghasilkan kompleks yang stabil yaitu membentuk ikatan koordinasi dan struktur cincin. Pembentukan ikatan melalui interaksi yang lebih lama terjadi apabila sisi aktif yang mengikat logam dengan kuat telah jenuh (Stevenson, 1994).

Kerndorf dan Schnitzer (1980) telah menguji interaksi 11 ion logam dengan asam humat, dan hasil yang diperoleh menunjukkan bahwa dengan meningkatnya $\mathrm{pH}$, efisiensi adsorpsi ion logam pada asam humat juga meningkat. Sedangkan efisiensi adsorpsi akan berkurang dengan berkurangnya konsentrasi logam.

Hasil penelitian Kerndoff dan Schnitzer, 1980 dalam Schnitzer, 1986 menunjukkan bahwa pada $\mathrm{pH}$ 2,4 urutan adsorpsinya adalah : $\mathrm{Hg}>\mathrm{Fe}>\mathrm{Pb}>\mathrm{Cu}=$ $\mathrm{Al}>\mathrm{Ni}>\mathrm{Cr}=\mathrm{Zn}=\mathrm{Cd}=\mathrm{Co}=\mathrm{Mn}$. Pada $\mathrm{pH}$ 3,7 mengikuti urutan $\mathrm{Hg}>\mathrm{Fe}>\mathrm{Al}>\mathrm{Pb}$ $>\mathrm{Cu}>\mathrm{Cr}>\mathrm{Cd}=\mathrm{Zn}=\mathrm{Ni}=\mathrm{Co}=\mathrm{Mn}$. Pada $\mathrm{pH}$ 4,7 mengikuti urutan $\mathrm{Hg}=\mathrm{Fe}=\mathrm{Pb}=\mathrm{Al}$ $=\mathrm{Cr}>\mathrm{Cd}>\mathrm{Ni}=\mathrm{Zn}>\mathrm{Co}>\mathrm{Mn}$. Pada $\mathrm{pH}$ 5,8 mengikuti urutan $\mathrm{Hg}=\mathrm{Fe}=\mathrm{Pb}=\mathrm{Al}=$ $\mathrm{Cr}=\mathrm{Cu}>\mathrm{Cd}>\mathrm{Zn}>\mathrm{Ni}>\mathrm{Co}>\mathrm{Mn}$.

Mekanisme adsorpsi tergolong kompleks, karena tidak hanya 11 ion logam dan $\mathrm{H}^{+}$(total 12 ion) yang berinteraksi dengan asam humat tetapi mereka juga berinteraksi satu sama lain. Mekanisme yang terlibat tampaknya mencakup pertukaran ion, kopresipitasi dan pembentukan kompleks lingkaran bagian dalam dan luar. Afinitas ion-ion tersebut pada asam humat tidak berkaitan dengan berat atom, nomor atom dan jari-jari ion terhidrat.

\subsection{Adsorpsi}

Menurut Oscik (1982) adsorpsi adalah proses akumulasi substansi adsorbat pada permukaan adsorben yang disebabkan oleh gaya tarik antar molekul atau interaksi kimia atau suatu akibat dari medan gaya pada permukaan padatan (adsorben) yang menarik molekul-molekul gas/uap atau cairan. Proses ini dapat terjadi sebagai proses fisika yang melibatkan gaya van der Waals dan ikatan hidrogen, dan selanjutnya dikenal dengan fisisorpsi atau dapat juga terjadi proses kimia yang melibatkan pembentukan senyawa kimia melalui ikatan kimia yang lebih kuat dan dikenal sebagai kemisorpsi.

Adsorpsi kimia melibatkan ikatan koordinasi sebagai hasil penggunaan bersama pasangan elektron oleh padatan (adsorben) dan adsorbat. Oscik (1982) mengemukakan bahwa pada adsorpsi fisika ikatan pada permukaan adsorben lemah dan bersifat reversibel, sehingga molekulmolekul yang telah teradsorp mudah lepas dengan cara menurunkan tekanan gas atau konsentrasi zat terlarut.

Pada proses fisisorpsi, di bawah kondisi suhu dan tekanan tertentu, lapisan adsorpsi yang terbentuk memiliki ketebalan beberapa diameter dari molekul adsorbat, 
sedangkan pada kemisorpsi hanya terbentuk lapisan tunggal (monolayer).

\section{Faktor-faktor yang mempengaruhi interaksi logam dengan adsorben}

Lyman dkk. (1995) dalam Sujandi (2002) mengemukakan bahwa gaya dorong adsorpsi permukaan merupakan kombinasi dua faktor, yaitu afinitas adsorbat terhadap pelarut dan afinitas adsobat pada adsorben. Kedua faktor ini dipengaruhi oleh :

a. Sifat logam dan ligan

Pendekatan sifat-sifat ion logam dan ligan dikembangkan oleh Pearson (1968) yang menggolongkan akseptor dan donor elektron ke dalam asam dan basa keras dan lunak. Jika adsorbat berupa kation logam dapat dinyatakan sebagai asam Lewis dan gugus-gugus fungsional pada adsorben sebagai basa Lewis, maka pengklasifikasian HSAB (hard soft acid and base) dapat diterapkan pada proses adsorpsi.

Secara umum, asam keras cenderung lebih stabil berikatan dengan basa keras, sedangkan asam lunak berikatan stabil dengan basa lunak. Fenomena ini berhubungan dengan energi orbital dari spesies-spesies tersebut.

b. Sifat Pelarut

Pada adsorpsi padat-cair, mekanisme adsorpsi bergantung pada faktor-faktor seperti gaya interaksi antara molekul adsorbat dengan permukaan, gaya interaksi antara molekul pelarut dengan permukaan adsorben, dan gaya interaksi antara molekul dari komponen larutan dengan lapisan permukaan adsorben dan pori-porinya (Oscik, 1982). Pelarut dapat ikut teradsorp atau sebaliknya dapat mendorong proses adsorpsi.

c. $\mathrm{pH}$ sistem

Pengikatan kation logam pada ligan permukaan, seperti halnya pengikatan kation logam oleh ligan terlarut sangat dipengaruhi oleh $\mathrm{pH}$. Pada $\mathrm{pH}$ rendah, ligan permukaan cenderung terprotonasi, sehingga kation logam juga berkompetisi dengan $\mathrm{H}^{+}$untuk terikat pada ligan permukaan. Sebaliknya pada $\mathrm{pH}$ tinggi dimana jumlah ion $\mathrm{OH}^{-}$besar, menyebabkan ligan permukaan cenderung terdeprotonasi, sehingga pada saat yang sama terjadi kompetisi antara ligan permukaan dengan ion $\mathrm{OH}^{-}$untuk berikatan dengan kation logam.

Menurut Jin dkk., (1996), adsorpsi ion logam pada situs aktif asam humat diasumsikan nonlinear dan mengikuti mekanisme Langmuir-Hinshelwood dengan order reaksi antara 0 dan 1 . Model kinetika diekspresikan dalam persamaan matematika berikut :

$$
\frac{\ln \left(C_{o} / C_{A}\right)}{C_{o}-C_{A}}+k_{o}=\frac{k_{1} t}{C_{o}-C_{A}}
$$

dimana $\mathrm{k}_{0}$ : konstanta laju reaksi order nol $(\mathrm{mol} / \mathrm{L})^{-1}, \mathrm{k}_{1}$ : konstanta laju reaksi order satu $\left(\min ^{-1}\right), \mathrm{C}_{\mathrm{o}}$ : konsentrasi ion logam awal, $\mathrm{C}_{\mathrm{A}}$ : konsentrasi ion logam sisa dalam larutan. Plot $\ln \left(\mathrm{C}_{\mathrm{o}} / \mathrm{C}_{\mathrm{A}}\right) /\left(\mathrm{C}_{\mathrm{o}}-\mathrm{C}_{\mathrm{A}}\right)$ terhadap $\mathrm{t} /\left(\mathrm{C}_{\mathrm{o}}-\mathrm{C}_{\mathrm{A}}\right)$, diperoleh garis lurus dengan slope $\mathrm{k}_{1}$ dan intersep $-\mathrm{k}_{\mathrm{o}}$.

Penerapan model kinetika di atas oleh Jin dkk., (1996), diperoleh bahwa semua intersep dari plot untuk adsorpsi ion tunggal maupun kompetitif menunjukkan nilai positif. Ini berarti $\mathrm{k}_{\mathrm{o}}$ akan berharga negatif untuk semua ion logam yang diamati. Namun ko yang diperoleh dituliskan bernilai positif.

Menurut Atkins, 1986 dan Masel, 1996 dalam Santosa (2001), model kinetika L-H harus memenuhi mekanisme L-H yaitu : (i) spesies adsorbat haruslah dua atau lebih, (ii) semua spesies harus pertama kali teradsorp pada adsorben, (iii) reaksi yang menghasilkan produk di antara adsorbat harus terjadi pada permukaan adsorben dan (iv) desorpsi produk dari permukaan adsorben (Santosa, 2001).

Berdasarkan alasan di atas, Santosa (2001) mengusulkan model kinetika baru yang menggambarkan adsorpsi ion logam pada asam humat. Model kinetika baru yang diusulkan adalah sebagai berikut:

$$
\frac{\ln \left(\frac{C_{A_{0}}}{C_{A}}\right)}{C_{A}}=k_{1} \frac{t}{C_{A}}+K
$$


Plot $\frac{\ln \left(\frac{C_{A_{0}}}{C_{A}}\right)}{C_{A}}$ terhadap $\mathrm{t} / \mathrm{C}_{\mathrm{A}}$ akan diperoleh garis lurus dengan slope $\mathrm{k}_{1}$ dan intersep $\mathrm{K}$. Untuk mengetahui kapasitas dan energi adsorpsi dapat dihitung berdasarkan model isoterm Langmuir sesuai dengan persamaan berikut :

$$
\frac{C}{m}=\frac{1}{b K}+\frac{C}{b}
$$

dimana $\mathrm{C}$ : konsentrasi adsorbat sisa dalam larutan, $\mathrm{m}$ : jumlah adsorbat yang teradsorp oleh adsorben, b : jumlah maksimum adsorbat yang mengisi adsorben, $\mathrm{K}$ : konstanta keseimbangan adsorpsi.

Plot $\mathrm{C} / \mathrm{m}$ terhadap $\mathrm{C}$ memberikan garis lurus dengan dengan slope $1 / \mathrm{b}$ dan intersep $1 / \mathrm{bK}$, sehingga tetapan $\mathrm{K}$ dan $\mathrm{b}$ dapat ditentukan. Berdasarkan harga $\mathrm{K}$, maka energi adsorpsi dapat dihitung menggunakan persamaan berikut :

$$
\mathrm{E}_{\mathrm{ads}}=\mathrm{R} \mathrm{T} \ln \mathrm{K}
$$

\section{METODE PENELITIAN \\ 3.1 Laju adsorpsi Cd(II) dan Pb(II)}

Proses adsorpsi dilakukan dengan metode batch. Sebanyak $10 \mathrm{mg}$ asam humat diinteraksikan dengan $50 \mathrm{~mL}$ larutan $\mathrm{Cd}$ (II) $50 \mathrm{mg} / \mathrm{L}$. Interaksi dilakukan pada $\mathrm{pH}$ optimum untuk adsorpsi $\mathrm{Cd}(\mathrm{II})$ pada adsorben asam humat. Campuran diaduk dengan pengaduk magnet. Kadmium(II) diinteraksikan dengan asam humat selama 5, 10, 20, 30, 45, 60, 90 dan 120 menit. Kemudian sampel disaring menggunakan kertas saring whatman 42. Konsentrasi Cd(II) terhidrat dalam filtrat ditentukan menggunakan Elektroda Selektif Ion (ESI), dan konsentrasi $\mathrm{Cd}$ (II) total dalam filtrat ditentukan dengan Spektroskopi Serapan Atom (SSA).

Konsentrasi Cd(II) yang teradsorp ditentukan dengan rumus: konsentrasi $\mathrm{Cd}$ (II) awal dikurangi dengan konsentrasi $\mathrm{Cd}$ (II) total pada filtrat. Sedangkan konsentrasi $\mathrm{Cd}(\mathrm{II})$ yang terkompleks dengan asam humat terlarut adalah: konsentrasi $\mathrm{Cd}(\mathrm{II})$ total pada filtrat dikurangi konsentrasi $\mathrm{Cd}(\mathrm{II})$ terhidrat pada filtrat. Untuk proses adsorpsi $\mathrm{Pb}$ (II) sama dengan logam $\mathrm{Cd}(\mathrm{II})$

\subsection{Isoterm adsorpsi $\mathbf{C d}(\mathrm{II})$ dan $\mathbf{P b}(\mathrm{II})$}

Proses adsorpsi dilakukan dengan metode batch. Sebanyak $10 \mathrm{mg}$ asam humat diinteraksikan dengan $50 \mathrm{~mL}$ larutan $\mathrm{Cd}(\mathrm{II})$ dengan konsentrasi 10, 20, 40, 60, 100, 150, 200, $300 \mathrm{mg} / \mathrm{L}$. pH larutan sistem diatur pada $\mathrm{pH}$ optimum untuk adsorpsi Cd(II) pada asam humat. Larutan campuran diaduk dengan pengaduk magnet dan diinteraksikan selama waktu yang diperlukan untuk mencapai keseimbangan yang diperoleh dari penentuan waktu adsorpsi $\mathrm{Cd}(\mathrm{II})$ pada asam humat. Kemudian supernatan dipisahkan dari padatannya dengan disaring menggunakan kertas saring whatman 42. Konsentrasi $\mathrm{Cd}$ (II) terhidrat dalam filtrat ditentukan menggunakan Elektroda Selektif Ion (ESI), dan konsentrasi $\mathrm{Cd}$ (II) total dalam filtrat ditentukan dengan Spektroskopi Serapan Atom (SSA).

Konsentrasi Cd(II) yang teradsorp adalah: konsentrasi $\mathrm{Cd}(\mathrm{II})$ awal dikurangi konsentrasi $\mathrm{Cd}(\mathrm{II})$ total. Sedangkan konsentrasi Cd(II) yang terkompleks dengan asam humat terlarut adalah: konsentrasi $\mathrm{Cd}(\mathrm{II})$ total pada filtrat dikurangi konsentrasi $\mathrm{Cd}(\mathrm{II})$ terhidrat pada filtrat. Untuk proses adsorpsi $\mathrm{Pb}$ (II) sama dengan logam Cd(II)

\section{HASIL DAN PEMBAHASAN \\ 4.1 Kinetika Adsorpsi $\mathrm{Cd}$ (II) dan $\mathrm{Pb}$ (II) pada Asam Humat}

Untuk mengetahui laju adsorpsi $\mathrm{Cd}(\mathrm{II})$ dan $\mathrm{Pb}$ (II) pada asam humat, dilakukan penelitian dengan cara menginteraksikan asam humat dengan $\mathrm{Cd}(\mathrm{II})$ dan $\mathrm{Pb}$ (II) dengan konsentrasi tertentu dan waktu interaksi yang bervariasi. Waktu interaksi yang diperlukan untuk mencapai keseimbangan adsorpsi dapat digunakan sebagai ukuran laju reaksi. Semakin sedikit waktu interaksi, maka semakin tinggi laju reaksi. Apabila keseimbangan adsorpsi telah tercapai, 
penambahan waktu interaksi tidak menambah jumlah logam yang teradsorp.

Oscik (1982) menyatakan bahwa adsorpsi dari fase gas maupun larutan umumnya adsorbat menuju ke permukaan adsorben dalam waktu relatif pendek, sedangkan keseimbangan adsorpsi memerlukan waktu yang lebih lama. Hasil penelitian pengaruh waktu interaksi terhadap adsorpsi $\mathrm{Pb}$ (II) dan $\mathrm{Cd}(\mathrm{II})$ pada asam humat ditunjukkan pada Gambar 1.

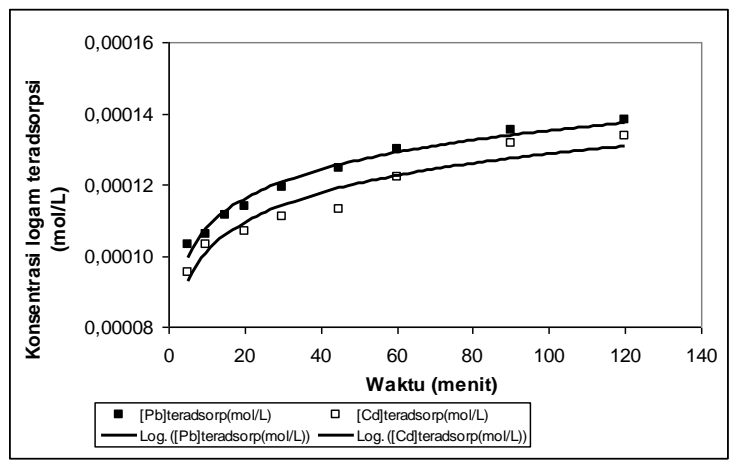

Gambar 1. Pengaruh waktu interaksi terhadap adsorpsi $\mathrm{Pb}$ (II) dan $\mathrm{Cd}$ (II) pada asam humat

Berdasarkan Gambar 1 terlihat bahwa adsorpsi $\mathrm{Cd}$ (II) dan $\mathrm{Pb}$ (II) pada asam humat memiliki kecenderungan yang sama yaitu terus meningkat dengan meningkatnya waktu interaksi dan adsorpsi berlangsung relatif cepat sebelum 5 menit. Pada interaksi 5-60 menit, baik Cd(II) maupun $\mathrm{Pb}(\mathrm{II})$ menunjukkan peningkatan adsorpsi yang cukup signifikan, namun demikian pertambahan waktu interaksi yang semakin besar relatif tidak menambah jumlah logam yang teradsorp. Dengan kata lain pertambahan jumlah logam yang teradsorp tidak sebanding dengan pertambahan waktu interaksi. Hal ini dapat dikatakan bahwa adsorpsi telah mencapai keseimbangan.

Telah diketahui bahwa, asam humat baik fraksi terlarut maupun fraksi tak larut dapat berinteraksi dengan ion logam. Oleh karena itu, pada penelitian ini juga dipelajari interaksi $\mathrm{Cd}$ (II) dan $\mathrm{Pb}$ (II) dengan asam humat baik fraksi tak larut maupun fraksi terlarut. Hasil penelitian pengaruh waktu interaksi terhadap spesiasi Cd(II) dan
$\mathrm{Pb}(\mathrm{II})$, yaitu $\mathrm{Cd}(\mathrm{II}) \quad$ dan $\quad \mathrm{Pb}(\mathrm{II})$ yang teradsorp, terhidrat maupun yang membentuk kompleks dengan asam humat ditunjukkan pada Gambar 2 dan 3.

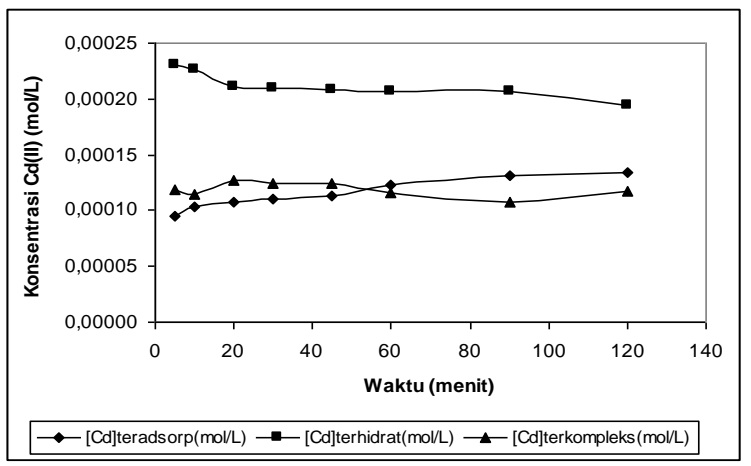

Gambar 2. Pengaruh waktu interaksi terhadap spesiasi Cd(II) dengan asam humat

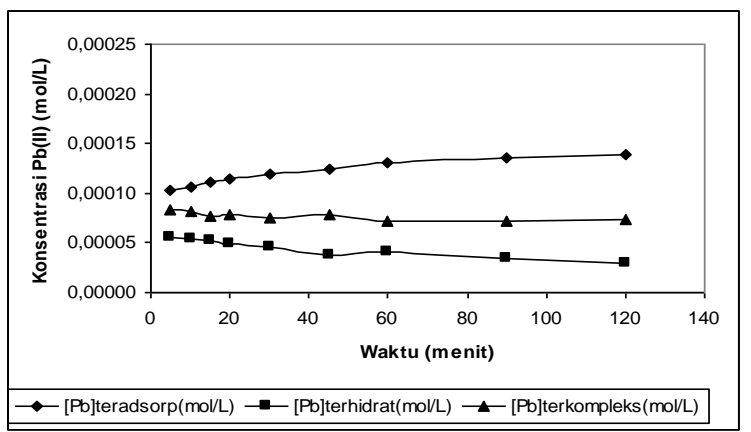

Gambar 3. Pengaruh waktu interaksi terhadap spesiasi $\mathrm{Pb}$ (II) dengan asam humat

Hasil penelitian yang terlihat pada Gambar 2 dan 3 menunjukkan bahwa jumlah $\mathrm{Cd}(\mathrm{II})$ dan $\mathrm{Pb}$ (II) yang membentuk kompleks dengan asam humat terlarut semakin menurun dengan meningkatnya waktu interaksi. Pada gambar tersebut juga terlihat bahwa proporsi jumlah Cd(II) yang membentuk kompleks Cd(II)-humat dengan jumlah logam $\mathrm{Cd}$ yang teradsorp hampir sama. Hal ini sangat berbeda dengan $\mathrm{Pb}(\mathrm{II})$, dimana $\mathrm{Pb}(\mathrm{II})$ lebih banyak yang teradsorp dibandingkan yang membentuk kompleks $\mathrm{Pb}$ (II)-humat. Hal ini mengindikasikan bahwa $\mathrm{Cd}$ (II) lebih mudah membentuk kompleks dibandingkan $\mathrm{Pb}(\mathrm{II})$. Mudahnya Cd(II) membentuk kompleks Cd(II)-humat dibandingkan $\mathrm{Pb}$ (II) kemungkinan disebabkan $\mathrm{Cd}(\mathrm{II})$ memiliki orbital terluar $\mathrm{d}$ yang energinya match (setara) dengan orbital atom donor (atom ligan) sehingga 
saat ligan mendekati $\mathrm{Cd}(\mathrm{II})$ terjadi pemisahan (splitting) orbital $\mathrm{d}$ dan dihasilkan energi. Energi inilah yang digunakan untuk membentuk kompleks Cd(II)-humat. Akibat pembentukan kompleks Cd(II)-humat, kemungkinan Cd(II) memiliki kemampuan 'membongkar' ikatan makromolekul asam humat baik antar maupun inter makromolekul asam humat, untuk membentuk ikatan $\mathrm{Cd}$ (II)humat terlarut.

Ikatan ion-ion logam dengan asam humat melibatkan proses yang kompleks seperti kompleksasi, khelat, interaksi coulomb, pembentukan garam dan pengendapan (Hayes dan Swift, 1978; Greenland dan Hayes, 1987 dalam Jin X dkk., 1996). Semua proses ini dapat dikarakterisasi sebagai bentuk perubahan energi. Berdasarkan pada studi fenomena nonlinear yang dilakukan para peneliti, menyatakan bahwa proses yang melibatkan berbagai bentuk energi dapat dikategorikan sebagai fenomena nonlinear. Proses-proses yang melibatkan plasma, protein, polimer organik, dan larutan secara umum mengikuti proses nonlinear. Demikian juga asam humat, sebagai makromolekul mengikuti proses nonlinear. Proses nonlinear digambarkan sebagai bentuk matematika yang menggambarkan interaksi dari fenomena fisik atau kimia dari makromolekul tersebut.

Model kinetika nonlinear LangmuirHinshelwood dapat digunakan untuk menggambarkan sorpsi ion-ion logam pada asam humat. Menurut Atkins (1986) dan Masel (1996) model kinetika L-H harus memenuhi mekanisme L-H yaitu: (i) spesies adsorbat haruslah dua atau lebih, (ii) semua spesies harus pertama kali teradsorp pada adsorben, (iii) reaksi yang menghasilkan produk di antara adsorbat harus terjadi pada permukaan adsorben dan (iv) desorpsi produk dari permukaan adsorben (Santosa, 2001).

Berdasarkan mekanisme L-H di atas, menjadi tidak realistis jika adsorpsi ion logam pada sistem larutan ion tunggal diasumsikan mengikuti model kinetika L-H.
Oleh karena itu Santosa (2001) mengusulkan model kinetika baru untuk menggambarkan adsorpsi kation logam pada asam humat berdasarkan penurunan persamaan isoterm Langmuir. Model persamaan tersebut adalah sebagai berikut :

$$
\frac{\ln \left(\frac{C_{A_{0}}}{C_{A}}\right)}{C_{A}}=k_{1} \frac{t}{C_{A}}+K
$$

Dengan membuat kurva linear $\frac{\ln \left(\frac{C_{A_{0}}}{C_{A}}\right)}{C_{A}}$ terhadap $\mathrm{t} / \mathrm{C}_{\mathrm{A}}$, dapat ditentukan harga $\mathrm{K}$ dan $k_{l}$ masing-masing dari intersep dan slope.

Penerapan model kinetika yang diusulkan Santosa (2001) memberikan data konstanta laju adsorpsi $\left(k_{l}\right)$ dan konstanta keseimbangan adsorpsi $(\mathrm{K})$ yang ditunjukkan pada Tabel 1.

Tabel 1. Parameter kinetika dengan menerapkan model kinetika yang diusulkan Santosa (2001) untuk adsorpsi Cd(II) dan Pb(II) pada asam humat

\begin{tabular}{|l|l|l|}
\hline \multirow{4}{*}{ Logam } & \multicolumn{2}{|l|}{$\begin{array}{l}\text { Parameter kinetika orde } \\
\text { satu yang mencapai } \\
\text { keseimbangan }\end{array}$} \\
\cline { 2 - 3 } & $\begin{array}{l}\mathbf{k}_{\mathbf{1}}(\mathbf{m e n i t} \\
\left.\mathbf{1}^{\mathbf{1}}\right) / \mathbf{1 0} \mathbf{~ m g ~ A H}\end{array}$ & $\mathbf{K}(\mathbf{m o l} / \mathbf{L})^{-\mathbf{1}}$ \\
\hline \hline $\mathrm{Cd}(\mathrm{II})$ & 0,0012 & 729,4 \\
$\mathrm{~Pb}(\mathrm{II})$ & 0,0038 & 4336,5 \\
\hline
\end{tabular}

Data Tabel 1 menunjukkan bahwa kecepatan adsorpsi $\mathrm{Pb}$ (II) lebih besar dibandingkan $\mathrm{Cd}(\mathrm{II})$. Berdasarkan harga $\mathrm{K}$ tersebut terlihat bahwa kemampuan asam humat mengadsorb $\mathrm{Pb}$ (II) lebih besar dibandingkan $\mathrm{Cd}(\mathrm{II})$.

Telah diketahui bahwa salah satu faktor yang mempengaruhi interaksi logam dengan adsorben adalah sifat ion logam dan jenis ligan. Lyman dkk. (1995) dalam Sujandi (2002) mengemukakan bahwa gaya dorong adsorpsi permukaan merupakan kombinasi dua faktor, yaitu afinitas adsorbat terhadap pelarut dan afinitas adsobat pada adsorben. 
Berdasarkan klasifikasi elektrofilnukleofil keras-lunak Pearson, $\mathrm{Pb}$ (II) termasuk dalam golongan elektrofil menengah (antara keras-lunak), sedangkan Cd(II) dikategorikan sebagai elektrofil lunak. Gugus karboksilat sebagai gugus utama asam humat yang berperan aktif dalam interaksi logam-asam humat yang mengalami deprotonasi merupakan nukleofil keras, sehingga $\mathrm{Pb}$ (II) lebih cepat dan mudah teradsorp dibandingkan Cd(II).

\subsection{Isoterm Adsorpsi $\mathrm{Pb}(\mathrm{II})$ dan $\mathrm{Cd}(\mathrm{II})$}

Isoterm adsorpsi merupakan hubungan keseimbangan antara konsentrasi adsorbat dalam fasa fluida dan konsentrasi adsorbat di dalam partikel adsorben pada temperatur tertentu. Untuk mempelajari isoterm adsorpsi $\mathrm{Pb}(\mathrm{II})$ dan $\mathrm{Cd}(\mathrm{II})$, diinteraksikan $10 \mathrm{mg}$ asam humat murni dengan $\mathrm{Pb}$ (II) dan $\mathrm{Cd}$ (II) pada berbagai konsentrasi selama 30 menit. Pola isoterm adsorpsi $\mathrm{Pb}$ (II) dan $\mathrm{Cd}(\mathrm{II})$ hasil penelitian ditunjukkan pada Gambar 4 dan 5.

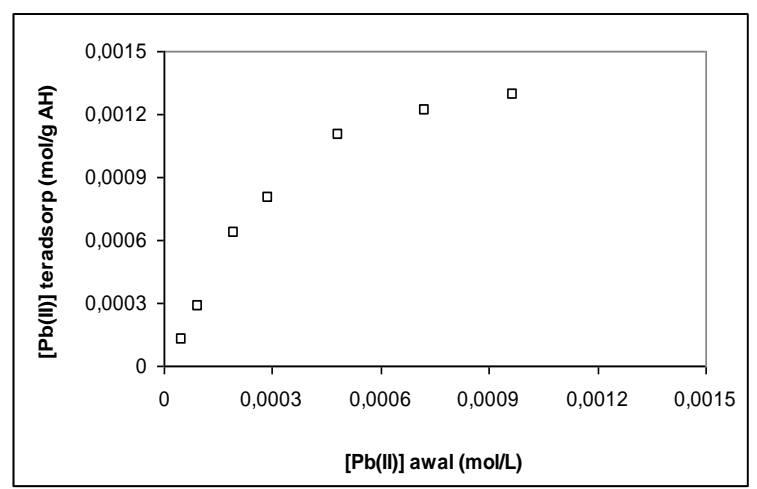

Gambar 4. Pola isoterm adsorpsi $\mathrm{Pb}$ (II)

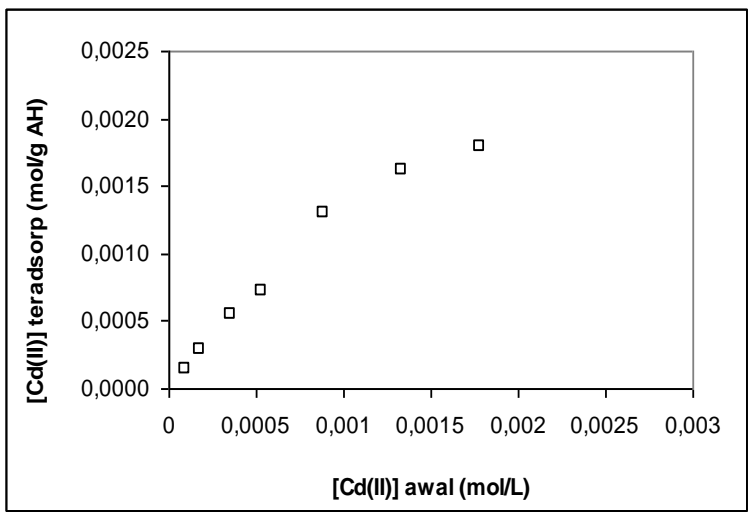

Gambar 5. Pola isoterm adsorpsi Cd(II)
Secara umum pola isoterm adsorpsi yang ditunjukkan pada Gambar 4 dan 5 menunjukkan terjadi kenaikan jumlah ion logam yang teradsorp per gram adsorben seiring dengan naiknya konsentrasi ion logam yang diinteraksikan. Pada konsentrasi aplikasi 100-200 mg/L, jumlah logam yang teradsorp relatif tidak bertambah, hal ini menunjukkan bahwa semua situs pada permukaan adsorben telah terisi penuh oleh adsorbat (ion logam). Dari Gambar 4 dan 5 menunjukkan bahwa proses adsorpsi berjalan mengikuti proses nonlinear, yaitu jumlah ion yang teradsorp dengan jumlah ion yang tidak teradsorp tidak proporsional atau tidak mengikuti suatu konstanta rasio yang konstan (Giddings, 1991).

Pada konsentrasi aplikasi Cd(II) rendah, jumlah logam yang teradsorp lebih kecil dibandingkan yang tidak teradsorp. Hal ini menunjukkan bahwa selain terjadi pembentukan ikatan Cd-situs aktif adsorben, kemungkinan juga diikuti proses pemutusan ikatan Cd-situs aktif (desorpsi). Rendahnya $\mathrm{Cd}(\mathrm{II})$ yang teradsorp pada asam humat pada konsentrasi aplikasi rendah juga disebabkan oleh banyaknya asam humat yang terlarut, untuk membentuk kompleks Cd-asam humat. Hal ini didukung dengan hasil penelitian bahwa pada konsentrasi aplikasi rendah, logam $\mathrm{Cd}$ yang membentuk kompleks $\mathrm{Cd}$-asam humat lebih besar dibandingkan yang teradsorp seperti ditunjukkan pada Gambar 6 .

Pada Gambar 6 juga terlihat bahwa dengan bertambahnya konsentrasi $\mathrm{Cd}(\mathrm{II})$ yang diaplikasikan, jumlah logam yang teradsorp maupun yang membentuk kompleks juga meningkat. Namun pada saat jumlah $\mathrm{Cd}(\mathrm{II})$ yang teradsorp pada asam humat mencapai nilai maksimum, logam Cd yang membentuk kompleks dengan asam humat semakin meningkat. Telah diterangkan sebelumnya bahwa Cd(II) sangat mudah membentuk kompleks Cd(II)-asam humat terlarut. Hal ini menjadikan dengan meningkatnya jumlah $\mathrm{Cd}$ (II) yang diinteraksikan dengan asam humat, $\mathrm{Cd}(\mathrm{II})$ sisa (yang tidak teradsorp) 
oleh padatan asam humat cenderung membentuk kompleks Cd(II)-asam humat.

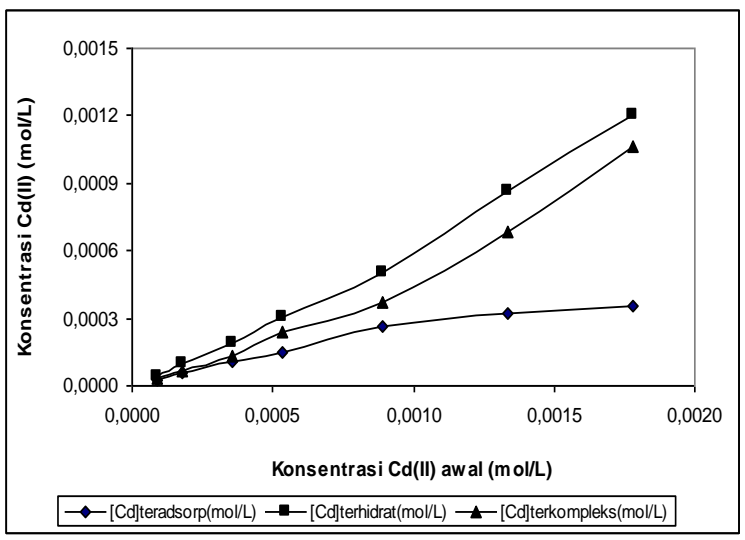

Gambar 6. Pengaruh konsentrasi awal Cd(II) terhadap spesiasi Cd(II) dengan asam humat

Hal sebaliknya terjadi pada $\mathrm{Pb}(\mathrm{II})$, pada konsentrasi aplikasi rendah (10-60 $\mathrm{mg} / \mathrm{L}$ ) jumlah $\mathrm{Pb}(\mathrm{II})$ yang teradsorp lebih besar dibandingkan yang tidak teradsorp yang ditunjukkan konsentrasi keseimbangan $\mathrm{Pb}$ (II) yang rendah. Hal ini didukung dengan hasil penelitian bahwa pada konsentrasi aplikasi rendah, $\mathrm{Pb}$ (II) yang membentuk kompleks $\mathrm{Pb}$ (II)-asam humat lebih kecil dibandingkan jumlah yang teradsorp seperti ditunjukkan pada Gambar 7.

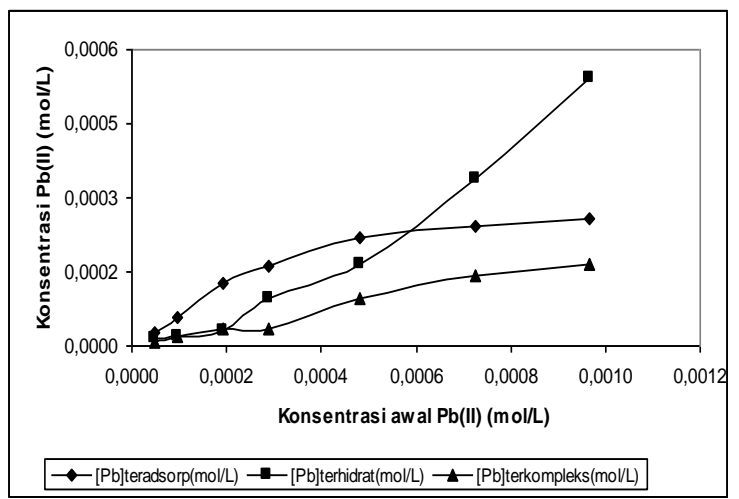

Gambar 7. Pengaruh konsentrasi awal $\mathrm{Pb}$ (II) terhadap spesiasi $\mathrm{Pb}(\mathrm{II})$ dengan asam humat

Dengan bertambahnya konsentrasi $\mathrm{Pb}$ (II) yang diaplikasikan, jumlah $\mathrm{Pb}$ (II) yang teradsorp maupun yang terkompleks dengan asam humat juga semakin meningkat, namun akhirnya konstan. Jumlah $\mathrm{Pb}$ (II) untuk teradsorp maupun membentuk kompleks dengan asam humat terlarut memberikan profil (kecenderungan) yang hampir sama. Hal ini sangat berbeda dengan pembentukan kompleks $\mathrm{Cd}(\mathrm{II})$ asam humat yang terus meningkat dengan bertambahnya konsentrasi $\mathrm{Cd}(\mathrm{II})$ yang diaplikasikan seperti ditunjukkan pada Gambar 7. Hal ini disebabkan kompleks $\mathrm{Pb}$ (II)-asam humat relatif kurang stabil jika dibandingkan dengan kompleks $\mathrm{Cd}(\mathrm{II})$ asam humat. Ketidakstabilan kompleks $\mathrm{Pb}$ (II)-asam humat, menjadikan $\mathrm{Pb}$ (II) yang tidak teradsorp cenderung dalam bentuk terhidrat. Hal ini didukung oleh interaksi dilakukan dalam medium air yang bersifat polar, dimana $\mathrm{Pb}(\mathrm{II})$ lebih tertarik atom $\mathrm{O}$ dari $\mathrm{H}_{2} \mathrm{O}$, menjadikan $\mathrm{Pb}$ (II) lebih banyak yang terhidrat.

Menurut Shaw (1980), jumlah keadaan maksimal yang ada menunjukkan jumlah lapisan adsorbat yang terbentuk pada permukaan adsorben. Jika keadaan maksimal berjumlah satu, maka adsorpsi tersebut mengikuti pola monolayer (lapis tunggal), sedangkan jika lebih dari satu, maka adsorpsi mengikuti pola multilayer.

Hasil yang diperoleh dari penelitian ini menunjukkan pola isoterm adsorpsi $\mathrm{Cd}(\mathrm{II})$ dan $\mathrm{Pb}$ (II) pada konsentrasi aplikasi $10-200 \mathrm{mg} / \mathrm{L}$ mengikuti pola monolayer.

\subsection{Kapasitas dan Energi Adsorpsi $\mathrm{Cd}$ (II) dan $\mathrm{Pb}$ (II)}

Pola isoterm adsorpsi $\mathrm{Cd}(\mathrm{II})$ dan $\mathrm{Pb}$ (II) hasil penelitian menunjukkan bahwa adsorpsi maksimum terjadi pada lapis tunggal (monolayer). Hal ini menunjukkan bahwa pola isoterm mengikuti pola isoterm adsorpsi Langmuir yang salah satu asumsinya adalah adsorpsi hanya terbatas pada pembentukan lapis tunggal (monolayer). Asumsi Langmuir yang lain adalah semua situs aktif adalah setara. Asumsi ini dapat dipenuhi dengan pendekatan bahwa gugus atau situs aktif dalam asam humat yang berperan dalam interaksi dengan kation logam adalah gugus - $\mathrm{COOH}$, dimana gugus inilah yang paling dominan mengalami deprotonasi pada $\mathrm{pH}$ interaksi baik $\mathrm{Cd}(\mathrm{II})$ maupun $\mathrm{Pb}$ (II). 
Penerapan persamaan isoterm Langmuir dapat digunakan untuk mengetahui kapasitas adsorpsi dan energi adsorpsi $\mathrm{Cd}(\mathrm{II})$ dan $\mathrm{Pb}(\mathrm{II})$ pada asam humat. Harga kapasitas adsorpsi ditentukan dari slope grafik $(1 / b)$, sedangkan besarnya energi adsorpsi ditentukan secara tidak langsung dengan menghitung harga $\mathrm{K}$ dari intersep grafik. Selanjutnya harga energi adsorpsi dapat dihitung dari harga $\mathrm{K}$ menurut persamaan :

\section{$\mathbf{E}_{\mathrm{ads}}=\mathrm{RT} \ln \mathrm{K}$}

Hasil perhitungan kapasitas adsorpsi, konstanta kesetimbangan (K) dan energi adsorpsi dengan menggunakan persamaan isoterm Langmuir ditunjukkan pada Tabel 2.

Tabel 2. Harga kapasitas adsorpsi (b), konstanta kesetimbangan (K) dan energi adsorpsi (E) yang dihitung dengan menggunakan persamaan isoterm Langmuir

\begin{tabular}{|l|l|l|l|}
\hline Spesies & $\mathrm{b}(\mathrm{mol} / \mathrm{g})$ & $\mathrm{K}(\mathrm{mol} / \mathrm{L})^{-1}$ & $\mathrm{E}(\mathrm{kJ} / \mathrm{mol})$ \\
\hline \hline $\mathrm{Cd}(\mathrm{II})$ & 0,00383 & 675 & 16,1 \\
$\mathrm{~Pb}(\mathrm{II})$ & 0,00166 & 5656 & 21,4 \\
\hline
\end{tabular}

Hasil penelitian menunjukkan bahwa kapasitas adsorpsi Cd(II) lebih besar dibandingkan $\mathrm{Pb}(\mathrm{II})$ Jika ditinjau berdasarkan teori HSAB Pearson, maka kapasitas $\mathrm{Pb}(\mathrm{II})$ yang teradsorp pada asam humat akan lebih besar dibandingkan $\mathrm{Cd}(\mathrm{II})$, dimana afinitas $\mathrm{Pb}$ (II) terhadap gugus-gugus fungsional asam humat (gugus - $\mathrm{COOH)}$ yang merupakan nukleofil keras lebih besar dibandingkan $\mathrm{Cd}$ (II) yang merupakan elektrofil lunak. Namun demikian hasil penelitian menunjukkan sebaliknya. Seperti telah dijelaskan sebelumnya bahwa $\mathrm{Cd}(\mathrm{II})$ sangat mudah membentuk kompleks dengan asam humat. Kemungkinan kompleks Cd(II)-humat yang terbentuk saling berikatan dengan kompleks Cd(II)-humat yang lain untuk membentuk sebuah agregat yang besar, sehingga air sebagai medium tidak mampu mensolvasi, akibatnya asam humat terlarut menjadi terendapkan, sehingga meningkatkan kapasitas adsorpsi Cd(II) pada asam humat. Hal ini didukung oleh penelitian yang dilakukan Liu dan Huang, yang mengamati struktur konformasi kompleks $\mathrm{Cd}(\mathrm{II})-\mathrm{AH}$. Hasil penelitian menunjukkan bahwa dengan meningkatnya logam $\mathrm{Cd}$ yang terkompleks dengan asam humat, meningkatkan agregasi asam humat. Ionion kadmium digambarkan berkoordinasi dengan gugus fungsional asam humat (gugus $-\mathrm{COO}^{-}$).

Hasil penelitian menunjukkan bahwa energi adsorpsi kedua logam relatif kecil. Namun demikian rendahnya energi adsorpsi ini tidaklah menunjukkan bahwa adsorpsi hanya berlangsung melalui interaksi fisika saja, tetapi menunjukkan kalau interaksi fisika ikut berperan dalam mekanisme adsorpsi selain interaksi secara kimia. Menurut Jin dkk. (1996), rendahnya energi adsorpsi ini dapat diakibatkan oleh mekanisme pengikatan ion logam pada asam humat bersifat kompleks akibat banyaknya jenis gugus fungsional asam humat yang dapat mengikat ion logam dan memiliki reaktivitas yang berbeda sehingga dapat mengikat ion logam melalui interaksi fisika maupun kimia. Hal ini sejalan dengan pendapat Stevenson (1994) yang menyatakan bahwa pengikatan ion logam dengan asam humat dapat terjadi melalui (i) pembentukan ikatan hidrogen atau jembatan air, (ii) interaksi elektrostatik dengan muatan negatif dari gugus $-\mathrm{COOH}$, (iii) pembentukan ikatan koordinasi dengan satu gugus donor dan (iv) pembentukan struktur khelat atau cincin, seperti kombinasi $\mathrm{COO}^{-}$dan $-\mathrm{OH}$ fenolat.

\section{KESIMPULAN}

a. Laju adsorpsi logam $\mathrm{Pb}$ (II) dan $\mathrm{Cd}$ (II) pada asam humat merupakan orde satu. Laju adsorpsi $\mathrm{Pb}$ (II) lebih besar dibandingkan $\mathrm{Cd}(\mathrm{II})$ dengan konstanta laju adsorpsi $\mathrm{Pb}(\mathrm{II})$ sebesar $3,8 \times 10^{-3}$ menit $^{-1}$ sedangkan Cd(II) sebesar 1,2 $\mathrm{x}$ $10^{-3}$ menit $^{-1}$. Timbal(II) merupakan elektrofil yang lebih keras dibandingkan $\mathrm{Cd}(\mathrm{II})$, hal ini mengakibatkan $\mathrm{Pb}$ (II) relatif lebih banyak dan lebih cepat 
teradsorp pada sisi aktif asam humat yang telah mengalami deprotonasi.

b. Isoterm adsorpsi $\mathrm{Cd}(\mathrm{II})$ dan $\mathrm{Pb}$ (II) pada asam humat mengikuti pola isoterm Langmuir. Kapasitas adsorpsi Cd(II) lebih besar dibandingkan $\mathrm{Pb}$ (II) masingmasing sebesar $3,83 \times 10^{-3}$ dan 1,66 $\mathrm{x}^{-3} \mathrm{~mol} / \mathrm{g}$. Hal ini disebabkan dengan meningkatnya $\mathrm{Cd}(\mathrm{II})$ yang membentuk kompleks $\quad \mathrm{Cd}$ (II)- $\mathrm{AH}$ telah meningkatkan agregasi asam humat, sehingga meningkatkan kapasitas adsorpsi Cd(II) pada asam humat.

c. Energi adsorpsi kedua logam relatif kecil yaitu sebesar 16,1 untuk logam Cd(II) dan 21,4 kJ/mol untuk logam $\mathrm{Pb}$ (II). Namun demikian rendahnya energi adsorpsi ini tidaklah menunjukkan bahwa adsorpsi hanya berlangsung melalui interaksi fisika saja, tetapi menunjukkan kalau interaksi fisika ikut berperan dalam mekanisme adsorpsi selain interaksi secara kimia.

\section{DAFTAR PUSTAKA}

Adamson, A.W., 1990, Physical Chemistry of Surfaces, Fifth Editions, John Wiley and Sons, Inc., New York.

Aiken, G.R., McKnight, D.M.,Wershaw, R.L. dan P. MacCarthy, P., 1985, "Humic Substance in Soil, Sediment and Water" : Geochemistry, Isolation, and Characterization, John Wiley \& Sons, New York.

Alberty, R.A., Daniels, F., penerjemah N.M Surdia, 1992, Kimia Fisika, Edisi kelima, Versi SI, Erlangga, Jakarta.

Alimin, 2000, "Fraksinasi Asam Humat dan Pengaruhnya pada Kelarutan Ion Logam Seng(II), Kadmium(II), Magnesium(II), dan Kalsium(II)”, Tesis, Program Pascasarjana, Universitas Gadjah Mada, Yogyakarta.

Avena, M.J. dan Koopal, L.K., 1999, Kinetics of Humic Acid Adsorption at Solid-Water Interfaces, Environ. Sci. Technol., 33: 2739-2744.
Chung, K.H., Seong W.Rhee, Hyun S.Shin, dan Christopher H.Moon, 1996, "Probe of Cadmium (II) Binding on Soil Fulvic Acid Investigated by ${ }^{113}$ Cd NMR Spectroscopy", Can. J. Chem, 74: 1360-1365.

Connel, D.W., dan Miller, G.J., Penerjemah Yanti Koestoer, 1995, "Kimia dan Ekotoksikologi Pencemaran”, UI Press, Jakarta.

Darmono, 1995, "Logam dalam Sistem Biologi Makhluk Hidup”, UI-Press, Jakarta.

Gardea, J.L.-Torresday, Tang, L., dan Salvador, J.M., " Copper Adsorption by Sphagnum Peat Moss and Its Different Humic Fractions", Proceedings of the $10^{\text {th }}$ Annual Conference on Hazardous waste Research, Texas.

Gosh, K., dan Schnitzer, M., 1980, "Macromolecular Structures of Humic Substances", Soil Science, 129

Hayes, M.B., dan Himes, F.L., 1986, "Nature and Properties of HumusMineral Complexes", In : "Interaction of Soil Mineral with Natural Organics and Microbes" (P.M. Huang dan M.Schnitzer), Soil Sci. Soc. Am. Special Publ., 17, Soil Sci. Am., Madison, WI : 103-158.

Huang, P. M.dan Schnitzer, M., 1986, "Interaction of Soils Minerals With Natural Organic and Microbes", Soil Sci. Soc. Am. Inc., New York.

Hunter K.A, Kim P.J, dan Reid R.Malcolm, 1999, "Factors Influencing the Inorganic Speciation of Trace Metal Cations in Fresh Waters", Mar.Freshwater Res., 50 : 367-372.

Jin, X., Bailey G.W., Yu, Y.S., dan Lynch, A.T., 1996, "Kinetics of Single and Multiple Metal Ion Sorption Processes on Humic Subtances", Soil Science, 161 : 509-519.

Kerndorff, H., dan Schnitzer, M., 1980, "Sorption of Metals on Humic Acid", Geochim. Cosmochim. Acta, 44 : 1577-1581. 
Kipton, H., Powell, J. and Town, R.M., 1992, "Solubility and Fractionation of Humic Acid, Effect of $\mathrm{pH}$ and Ionic Medium", Anal. Chim. Acta, $267: 47-54$.

Liu Aiguo dan Gonzales, R.D., 2000, "Modeling Adsorption of Copper(II), Cadmium(II) and Lead(II) on Purified Humic Acid", Langmuir, 16 : 3902-3909.

Liu C. dan Huang, P.M., 1999, "Atomic Force Microscopy of $\mathrm{pH}$, Ionic Strength and Cadmium Effects on Surface Features of Humic Acid", In : "Understanding Humic Substances" : Advanced Methods, Properties and Applications, The Royal Society of Chemistry, Cambridge, UK.

Manahan, S.E., 2000, "Environmental Chemistry", Seventh Edition, Willard Grant Press, Boston.

Ościk, J., 1982, “Adsorption”, John Wiley \& Sons, New York.

Sanchez-Cortez, S., Francioso, O., GarciaRamos, J.V., Marzadori, C., and Gessa, C.C.C., 2000, "Formation of Humic-like substances from Phenols by means SERS Spectroscopy, p.121, In : Proceedings $10^{\text {th }}$ International Meeting of the International-Humic Substances Society, IHSS 10, 24-28 July 2000Touluse (France).

Santosa, S.J., 2001, "Adsorption Kinetics of $\mathrm{Cd}(\mathrm{II})$ and $\mathrm{Cr}(\mathrm{III})$ by Humic Acid", dalam Prosiding Seminar Nasional Kimia IX, Jurusan Kimia Universitas Gadjah Mada, Yogyakarta, 21 Mei 2001.

Schnitzer, M., 1986, “Pengikatan Bahan Humat oleh Koloid Mineral Tanah", (dalam Huang, P.M, dan Schnitzer, M., 1986, "Interaksi Mineral Tanah dengan Organik Alami dan Mikroba", Terjemahan : Goenadi, D.H., 1997), Gadjah Mada University Press, Yogyakarta.

Schlebaum, W., 1999, "Organic Contaminants in Soil Desorption
Kinetics and Microbial

Degradation", Wageningen.

Senesi, N., 1994, "Spectroscopic Studies of Metal Ion Humic Substance Complexation in Soil', In : $15^{\text {th }}$ World Congress of Soil Sci., Acapulco, Mexico.

Spark, K.M., Wells, J.D., dan Johnson, B.B., 1997, "The Interaction of Humic Acid With Heavy Metals", Aus. J. Soil Res., 35 : 89-101.

Stevenson, F.J., 1994, "Humus Chemistry: Genesis, Composition, Reactions", John Wiley \& Sons Inc., New York.

Stumm, W dan Morgan, J.J, 1996, "Aquatic Chemistry", Third Edition, John Wiley \& Sons, Inc, New York.

Sudiono, S., Narsito, dan Santosa, S.J., 2001, "Studi Interaksi Asam Humat dengan $\mathrm{Cu}(\mathrm{II})$ dan $\mathrm{Ni}(\mathrm{II})$ ", dalam Prosiding Seminar Nasional Kimia $I X$, Jurusan Kimia Universitas Gadjah Mada, Yogyakarta, 21 Mei 2001.

Varrault, G., Camel, V., and Bermond, A., 2000, Adsorption of Trace Metal Ion onto Humic Acid, p. 587-588, in: Proceedings $10^{\text {th }}$ International Meeting of the International-Humic Substances Society, IHSS 10, 24-28 July 2000-Touluse (France).

Zavarzina, A.G., Demin, V.V., 2000, Complexation of Molecular-Size Fractionated Humic Acids with Zink and Cadmium, p. 649-654, in: Proceedings $10^{\text {th }} \quad$ International Meeting of the International-Humic Substances Society, IHSS 10, 24-28 July 2000-Touluse (France). 